\title{
Facebook's "Free Basics" and Implications for Development: IT Identity and Social Capital
}

\author{
Moonjung Yim \\ University of Washington \\ mjyim@uw.edu
}

\author{
Ricardo Gomez \\ University of Washington \\ rgomez@uw.edu
}

\author{
Michelle Carter \\ Washington State University \\ michelle.carter@wsu.edu
}

\begin{abstract}
Facebook's Free Basics has been controversial among researchers in the fields of information and communication technologies for development (ICTD) and community informatics (CI). What is the nature of Free Basics' potential contribution to individual and community development? We explore this question by analyzing different uses of Facebook-one of the forefront services provided through Free Basics - and their relation to information technology (IT) identity and social capital. We find that, while issues and concerns surrounding Free Basics exist-e.g. restrictions on participants' choices in accessing and using information, possible privacy risks, and potential societal costs-there is room for positive aspects in broader use of Facebook, despite its potential pitfalls. We suggest ways to analyze both the contradictions and contributions of Free Basics to individual and community development, and examine implications for ICTD and sustainable development in general.
\end{abstract}

\section{Introduction}

In 2013 Facebook launched Internet.org initiative "with the goal of bringing internet access and the benefits of connectivity to the two-thirds of the world that doesn't have them." [1] The attempt at making Facebook synonymous with the internet drew much criticism, and merging Facebook's agenda with social good ("The more we connect, the better it gets" [2]) was especially egregious to researchers and practitioners in the fields of information and communication technologies for development (ICTD or ICT4D) and community informatics (CI). In late 2015, faced with a global backlash and withdrawal of several web publishers [3], Facebook renamed the app that is a central part of the initiative from Internet.org to "Free Basics". From its website, Internet.org:
Free Basics by Facebook provides people with access to useful services on their mobile phones in markets where internet access may be less affordable. The websites are available for free without data charges, and include content on things like news, employment, health, education and local information. By introducing people to the benefits of the internet through these websites, we hope to bring more people online and help improve their lives. [4]

The backbone of Free Basics services is free access to Facebook content, plus several additional sites without data charges. By mid-May 2016, Free Basics had launched in 40 countries, mostly in Africa and Middle East [5].

Some suggest that since there appears to be general agreement that ICTs are relevant for the developing world, we should instead examine how ICTs can be beneficial [6], [7] (cited from [8]). This paper takes a more critical stance. We argue that ICTs may or may not be relevant in development contexts and we need to understand what characteristics of an ICT make it relevant as a potential enabler of development. We believe that doing so would help uncover reasons why we have witnessed such a limited success, despite significant efforts to harness the power of information and technology to enrich people's lives (for some examples of recent literature reviews see [9]-[12]). Moreover, we consider Free Basics a particularly worthwhile ICT to examine in depth: Facebook is not simply a new player in ICTD and CI's mission to help improve the world through better access and effective use of information technologies; Facebook is a different kind of player, with bigger pockets. Further, it can be argued that the company has a commercial agenda to get more users to see and experience the world through the lens of Facebook.

We have been intrigued by the contention that more Facebook can lead to more development [13]. We also perceive the need to examine the relationship between Facebook the social networking site (SNS) and development as it is becoming increasingly 
embedded in people's lives in developing nations: As an example, during a 2015 encounter between one of this study's authors and an indigenous person in a South American country, the person mentioned that although he's not an expert in ICT, he just knows the basics: Word, Google, and Facebook. For him, Facebook was already part of the basic ICT in everyday use.

Information technology (IT) identity refers to "the extent to which an individual views use of an IT as integral to his or her sense of self" [14, p. 932]. With widespread use of IT across personal, work, and global boundaries, examining how people view themselves in relation to technologies is important for understanding the effects of ICTD initiatives. To continue the conversation on Facebook's Free Basics from a recent heated online debate, which took place through a CI listserv

(http://vancouvercommunity.net/lists/info/ciresearche rs), we draw from our work on IT identity and ICTD to offer this opinion piece that explores the following research question: What is the nature of Free Basics' potential contribution to individual and community development?

In terms of defining development, this paper aligns with Sen's notion of Capability Approach, where development is defined as "a process of expanding the real freedoms that people enjoy" to pursue "the kind of lives they value - and have reason to value" [15, pp. $3,18]$. This entails perceiving development as a person or a group possessing capabilities and competencies to pursue what they seek as meaningful in their lives. From this viewpoint, we believe the notion of development equates with empowerment at the individual level and social capital at the collective or communal level. With this understanding of development, we address the research question through analysis of one of the forefront services offered through Free Basics, i.e., Facebook, and then extend the Free Basics discussion to the broader context of ICTD. The concepts of IT identity [14] and social capital are used as an analytical framework for uncovering relationships between Facebook use and indicators of individual and community development, namely: IT identity formation, empowerment, and social capital creation. Moreover, authors were inspired by a panel discussion in Hawaii International Conference on System Sciences (HICSS) 2016 [16] in applying IT identity theory to the issues of technology and development and this work is a continuation of the effort.

The rest of the paper proceeds as follows: First, we present the main themes identified in the CI listserv discussion about Facebook's Free Basics. Next, we describe the core ideas underpinning the conceptualization of IT identity [14]. Following this, we explore different notions of social capital. Then, we present a typology of Facebook use. We bring these elements together to evaluate Facebook's (and Free Basics') potential contributions and limitations to individual and community development. Specifically, using IT identity as a theoretical lens, we map Facebook uses onto two dimensions: "Degrees of Self" (from IT identity) and "Forms of Social Capital" (bridging, bonding, and maintained) to illuminate relationships between types of use, IT identity, and social capital. We conclude with implications for ICTD and CI researchers.

\section{Community informatics' perspectives on Facebook's Free Basics}

Though Facebook the SNS seems to be by far the most prominent of the services offered through Free Basics, the creator of Free Basics has emphasized the openness of the platform: "Anyone can add their website to the Free Basics Platform so long as they abide by our participation guidelines, which exist to optimize for performance on older phones and slower network connections." [17]

Despite the claims to openness and inclusiveness, the introduction of Free Basics has been controversial in many development circles. We cannot present all aspects of the discussion and this is beyond the scope of this study. However, to provide a background to the Free Basics debate and to illustrate the major concerns among researchers, we herein include CI researchers' listserv discussion on Free Basics during December 2015 and January 2016 - to which one of the authors of this paper had access as a member. It exhibited an unusually active set of discussion threads involving proponents and opponents of the platform and the discussions often extended to issues surrounding Facebook as the company and the SNS. The discussion covered a broad range of topics, and following the scope of study, quotations were selected where the discussants presented clear and strong arguments for or against Free Basics.

From the proponent's side, there were discussions about potential benefits that Free Basics can provide to its users. One participant highlighted that "Free Basics provides free access to essential internet services like communication, education, healthcare, employment, farming[,] and more" and that the platform "helps those who can't afford to pay for data, or who need a little help getting started online." He/she added that " $[\mathrm{I}]$ personally went and met people who are using [F]ree [B]asics, for them it is a necessity, for them getting weather information is a necessity, for 
students who can't afford internet Wikipedia is a necessity..." There were also comments claiming that what is significant for community development is "the ability for people to participate in networks" and that one cannot "isolate Free Basics from the vital community aspects of the Free Basics end users."

In contrast, opponents expressed concerns about the social media giant's ability to selectively provide and manipulate information. A participant asserted that in community internet setting, people "should be able to be selective on promoting local content, and other kind of preferred content, as locally determined, in clear pursuance of community interest and autonomy..." This implies the argument that information provided through Free Basics — operated by a private company-may not truly reflect communities' demands, and that the platform may negatively influence communities' freedom to determine which information is meaningful for them. Another claimed that " $[\mathrm{t}]$ he particular problem with Facebook owning all the media that people are exposed to is definitely something to think about, given the company's history with manipulation of the newsfeed..." One participant argued for alternative approaches to Free Basics, e.g. "government providing a free quota of data to every citizen, that can be used for accessing the 'full Internet'."

If we examine the discussion in closer detail, we can see that the participants are pointing out themes that are not only applicable to Free Basics case but also relevant to ICTD in general: Some stress the importance of people's access to, and use of, information and others question by whom and how information should be provided and controlled.

One might be curious about the linkage between Free Basics and development. From the descriptions on the Internet.org website and the CI listserv discussion, we perceive that, at least on the surface, some common objectives are claimed by both Free Basics and ICTD, namely: promoting access to, and exchange of, information, enabling users to (i) create and enhance social networks and (ii) use information and technology in meaningful ways for themselves. Also, we are aware that from the history of ICTD and debates on Facebook's operation, information technologies (whether ICT at large, restricted to Facebook or expanded to Free Basics) have generated consequences that may or may not match with their supposedly original intentions of enriching people's lives. In these aspects of objectives and limitations, we can see that Free Basics and ICTD share some common ground.

Before we delve into the possible implications of Free Basics for development, we will develop our analytical framework: First, we will discuss IT identity as a theoretical construct. Second, we will describe different forms of social capital. Third, we will outline a typology of Facebook use. Finally, we will map the typology of Facebook use against the dimensions of IT identity and social capital. Doing so will offer a basis to evaluate the claims in favor and against Free Basics and its potential contribution to development.

\section{First dimension: "Degrees of Self" in IT identity theory}

We chose IT identity theory [14] to form the first dimension of our analytical framework because, with respect to the individual and collective realms of IT use, the theory shares common ground with ICTD.

The process of IT identity formation is initiated by an individual when he/she perceives the potential for self-expansion through a certain technology. If the person experiences a rapid increase in his/her sense of efficacy through intense uses of the technology, the individual would perceive use of the IT as integral to his/her sense of self and he/she would utilize the technology to solve various life's problems - leading to the formation of IT identity. By then he/she experiences losses of capabilities if detached from the technology — as if a part of the self is lost.

Although IT identity formation takes place at the individual level, it is related to the social structures which people are associated with. To illustrate, in a society, certain IT use patterns may emerge at the collective level as individuals use the technology in meaningful ways for themselves and these uses extend to surrounding groups of people. These patterns form shared expectations which individuals internalize as IT identities with regard to their own behaviors. Therefore, expression of IT identity and its social impact extend beyond the individual, to the collective realm.

IT identity formation processes in the individual and collective realms are also applicable to ICTD. In terms of ICTD's goals, the language is translated as individual empowerment for the individual realm and social capital creation for the collective realm. Putting together the notions of ICTD and IT identity, the central question of ICTD can be described as: Can we promote innovative actions through technologies which would create patterns of behavior amongst the empowered individuals in a social group, and eventually raise the social capital of the society through a bottom-up approach?

In sum, IT identity formation involves processes in the individual and collective realms and this provides the IT identity theory the capability to examine the 
implications of people's IT use for individual and community development.

In a previous research that analyzes undergraduate students' self-identification with mobile phones, Carter et al. [18] found three different types of meanings that the students develop as mobile phone uses become increasingly embedded across various aspects of their lives: functional, relational, and selfidentification meanings. Carter et al. [18] found that, young adults who primarily use mobile phone as a means to communicate with others tend to focus on functional attributes, such as device features (functional meanings). The authors found that the use of mobile phones takes on new meaning as the young adults rely on the device for maintaining and enhancing social relationships and group memberships. Here, the young adults become attentive to what they mean to others in their social circle through the use of mobiles (relational meanings). Lastly, as the young adults utilize many different features of mobile phones and apply them in a wide range of situations and relationships, he/she may describe the device as being part of oneself and of being "lost" or "not real" without it (self-identification meanings). Functional, relational, and self-identification meanings illustrate the degree to which an individual regards a certain technology as part of oneself. Forming IT identity necessarily involves each of these sets of meanings, as a person experiences a technology being increasingly embedded in one's everyday life. Based on the above, the first dimension of our analytical framework consists of the three meanings and is labeled, "Degrees of Self". In the following section, we describe the second dimension of our framework, "Forms of Social Capital".

\section{Second dimension: "Forms of Social Capital"}

In terms of its purposes, social capital can be defined as the following:

"Social capital...is not a single entity but a variety of different entities, with two elements in common: they all consist of some aspect of social structures, and they facilitate certain actions of actorswhether persons or corporate actors - within the structure. Like other forms of capital, social capital is productive, making possible the achievement of certain ends that in its absence would not be possible." [19]

In this definition we can see that social capital is closely related with facilitating productive actions by people. Accordingly, social capital creation can be described as important driving force behind community development.

In this paper, we examine three different forms of social capital: bridging, bonding, and maintained. First, Putnam [20] describes bridging social capital as outward looking, inclusive connections where people from varying backgrounds form weak ties and benefit from "generat[ing] broader identities and reciprocity" $[20$, p. 23]. He describes that networks creating bridging social capital can be helpful for disseminating information and obtaining assets that exist external to one's intimate connections. Regarding bonding social capital, Putnam [20] describes it as inward looking, exclusive strong ties consisting of people from similar backgrounds. He mentions that this type of social connection can be beneficial for "mobilizing solidarity" and "provid[ing] crucial social and psychological support" [20, p. 22]. In terms of classifying different social networks into the two forms of social capital and making the distinction between bridging and bonding, Putnam [20] states the following:

"...bonding and bridging are not 'either-or' categories into which social networks can be neatly divided, but 'more or less' dimensions along which we can compare different forms of social capital... On the other hand, we must keep [the] conceptual differentiation at the back of our minds...recognizing that bridging and bonding social capital are not interchangeable." [20, pp. 2324]

Based on Putnam's [20] conceptualization, Williams [21] came up with specific characteristics of bridging and bonding social capital. According to the author, bridging social capital is characterized by emphasis on outward looking; contact with a broad range of people; a view of oneself as part of a broader group; and diffuse reciprocity with a broader community. In contrast, Williams [21] claims that bonding social capital can be portrayed as networks that provide and generate emotional support; access to scarce or limited resources; ability to mobilize solidarity; and out-group antagonism.

A third form of social capital was introduced by Ellison et al. [22] as maintained social capital. This is defined as "the ability to maintain valuable connections as one progresses through life changes" [22, p. 1146]. According to Ellison et al. [22], this form of social capital allows examining "whether online network tools enable individuals to keep in touch with a social network after physically disconnecting from it." [22, p. 1146] The authors mention an example case demonstrating maintained social capital as college students trying to maintain social network that they have formed in high school back in their hometown. 
To summarize, bridging social capital involves weak ties formed among people from different backgrounds, bonding social capital involves strong ties such as close friends and family, and maintained social capital examines how one continues to be part of social connections as changes in life take place. These three "Forms of Social Capital" comprise the second dimension of our analytical framework. The two dimensions can be visualized as a diagram (see Figure 1), which we will populate with an analysis of the potential contribution of Free Basics (in which Facebook is the forefront SNS service) to different Degrees of Self and different Forms of Social Capital, differentiating the types of use. Thus, the following section derives different types of Facebook use and maps them onto the dimensions of Facebook use.

\section{Typology of Facebook use}

In this study, we use Facebook to explore the potential contributions and limitations of Free Basics because Facebook is one of the foremost SNS services provided in Free Basics. Of the many studies suggesting a typology of Facebook (or similar SNS) use and/or user, we found the works of Joinson [23] and Brandtzæg [24] particularly insightful and useful to our analysis.

Joinson [23] analyzed different uses of Facebook and asked participants questions such as "[w]hat is the first thing that comes to mind when you think about what you enjoy most when using Facebook?" and "[w]hat uses of Facebook are most important to you?" [23, p. 1029]. From answers to the first question, Joinson [23] generated eight themes of use and from responses to the second, identified 28 different Facebook uses.

Brandtzæg [24] studied social implications of Norwegians' use of SNS. Although the study was not specific to Facebook, it provided insights into the types of activities that individuals can engage in on the platform-a list of 32 items, supportive and complementary to those generated by Joinson [23], were identified.

We combined Joinson's [23] and Brandtzæg's [24] typologies, to identify eight different categories or types of use: Surveillance Oriented, Consumption Oriented, Event Oriented, Media Uploading Oriented, Contact Oriented, Group Oriented, Discussion Oriented, and Status Update Oriented. These eight categories are helpful for mapping Facebook uses in relation to social capital and IT identity. Each category is described, in brief, below:
- Surveillance Oriented: Includes activities that are watching or viewing people, without communicating with them.

- Consumption Oriented: Describes a type of use that is mostly related to users' intake of various kinds of information.

- Event Oriented: Involves uses that are geared towards organizing, joining, arranging or adding events or appointments.

- Media Uploading Oriented: Consists of posting or sharing pictures/photographs, music, movies/videos.

- Contact Oriented: Consists of "Making new contacts", "Re-acquiring lost contacts", "Communication", "Perpetual contact", and "Keeping in touch"; describes types of Facebook use that focus on communicating with other people in various kinds of relationships, ranging from acquaintances to close family or friends.

- Group Oriented: Indicates a type of use that aims to gather people to form a group or to facilitate communication among likeminded people.

- Discussion Oriented: Includes cases when the platform is used to produce writings that express one's opinion regarding an issue and/or to facilitate debates on various matters such as for political reasons.

- Status Update Oriented: Takes place where an individual expresses oneself via updating or changing profiles or status of one's own.

In our next step, we identified the Degrees of Self [18] and Forms of Social Capital [20]-[22] that each category of use was associated with. Then, we created a visual representation of these relationships. Figure 1 shows where the categories of use were located on our analytical framework. 


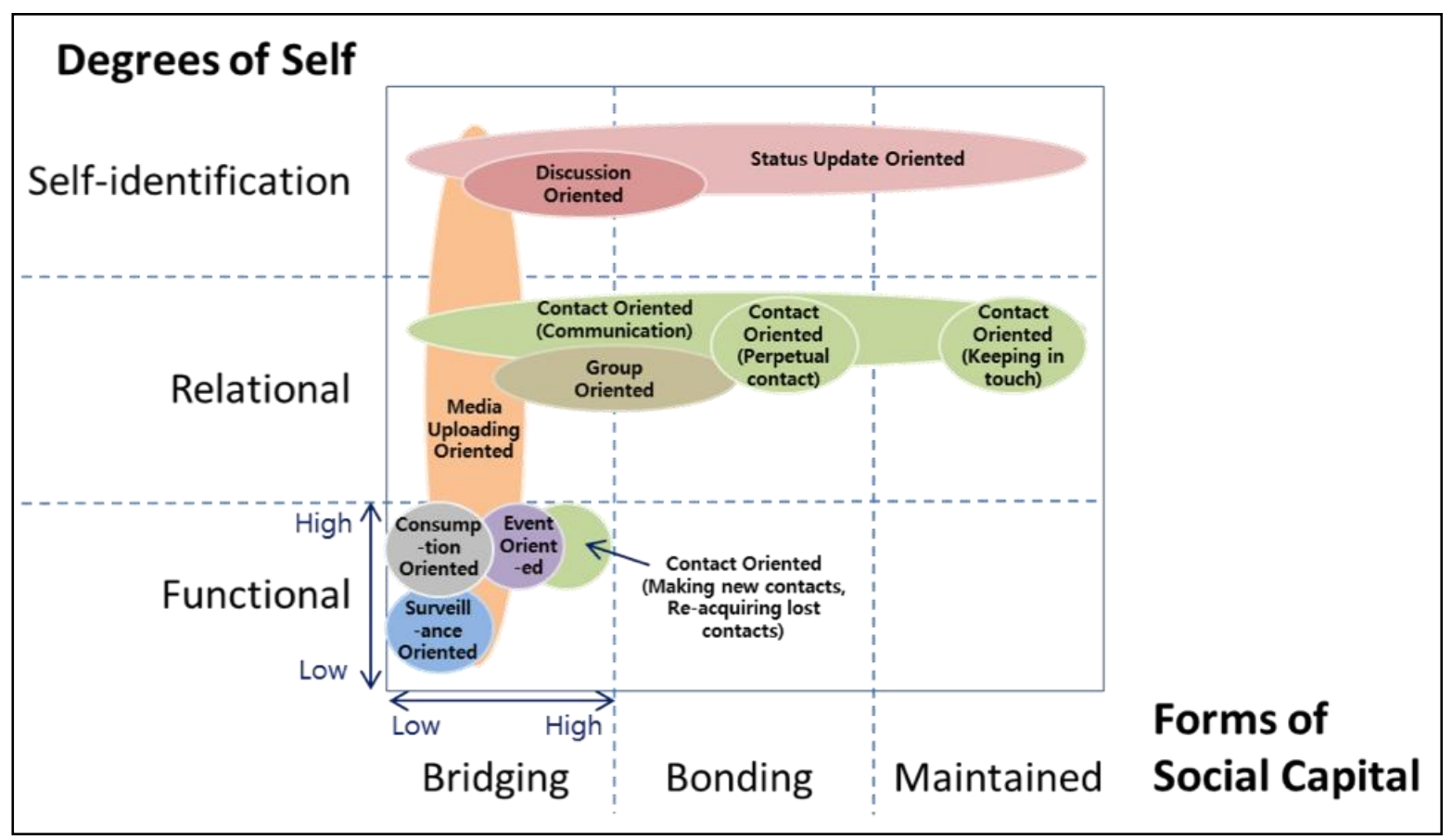

Figure 1: Dimensions of Facebook use

Uses with functional meanings (Surveillance Oriented, Consumption Oriented, Event Oriented, Contact Oriented (Making new contacts, Re-acquiring lost contacts), Media Uploading Oriented (e.g. posting landscape or scenery photos)) are largely related to information consumption or creation without much direct and in-depth interaction with others. Here, Facebook provides a means of accessing a social network, or consuming and/or uploading information for personal benefit and satisfaction. In general, users that engage in these categories of use do not give away much personal information relative to the amount of information accessed.

Uses with relational meanings (Group Oriented, Contact Oriented (Communication, Perpetual contact, Keeping in touch), Media Uploading Oriented (e.g. tagging family members in photos)) entail information sharing or creation that involves direct and in-depth interaction with others. Here, users gain and create information that is meant to be shared with others. As a result, they may gain a sense of belonging to a certain social network. As the information shared reveals one's affiliation and relationship with others, a user discloses more personal information compared to when he/she engages in uses related to functional meanings.

Through types of use with self-identification meanings (Discussion Oriented, Status Update Oriented, Media Uploading Oriented (e.g. uploading a picture of him-/herself)), a user experiences an expansion of oneself through Facebook, as he/she expresses views and announces information about him-/herself. In return, the user discloses much of his/her personal information.

Furthermore, different forms of social capital are exhibited in the uses. We discuss these in the following section.

\section{Implications of Free Basics for individual and community development}

Based on the above analysis, we can derive implications for Facebook's Free Basics (and perhaps ICTD projects in general). First, at the individual level, Figure 1 illustrates that a person's Degrees of Self in terms of IT identity formation might influence the types of Facebook use, and ultimately the range of social networks that one would engage through Facebook use. For instance, a person who focuses on functional attributes of Facebook (functional meanings) would be mostly engaged in activities that are Surveillance Oriented, Consumption Oriented, Event Oriented, Contact Oriented (Making new contacts, Re-acquiring lost contacts), or Media Uploading Oriented, more so than Discussion Oriented or Status Update Oriented activities (related to self-identification with technology). This in turn would mean that the individual would be participating in social connections related to bridging social capital more so than that related to bonding and maintained social capital from the Facebook use. For ICTD 
projects in general, this may imply that an implementer cannot assume a certain form of social networks would be created by individuals based on an ICT's features and functions, and should instead take into consideration the level of IT identity formation by the target participants.

Related to the above, at the societal level, Figure 1 implies that providing access to technology and information through Free Basics itself may not be a sufficient condition to generate various different forms of social capital. What may deserve more attention is how behaviors associated with different types of Facebook use exhibited at the individual level leads to social capital creation and thus community development. In terms of ICTD, this would imply that although providing access to ICT can be an initial step (opening gates to form functional meanings in relation to ICT), whether the actual takeoff can take place for a society to experience a range of different forms of social capital is largely dependent on its members' IT identity formation and related Facebook usage patterns. This also implies that there is a connection between individual empowerment (illustrated as IT identity formation) and social capital formation.

Additionally, Figure 1 illustrates that depending on one's Degrees of Self and related types of Facebook use that one is mostly engaged with, individuals might be releasing different levels of personal information by using Facebook. For example, an individual who is primarily engaged in Consumption Oriented types of use (related to functional meanings) would be revealing less of his/her personal information compared to an individual who is primarily involved in Status Update Oriented use (related to selfidentification with technology). This may also apply to ICTD project undertakings in that the issue of personal information release might vary among different people according to an individual's position on Degrees of Self dimension.

In summary, our analysis of Figure 1 informs us the following for Facebook, and more broadly, for ICTD: that the context in terms of the level of IT identity formation is crucial for Facebook or an ICTD project to contribute to social capital creation; that there is a connection between promoting individual empowerment and generating social capital; that merely providing access to technology and information might not be a sufficient condition to fulfill community development goals; and that issues surrounding personal information release would differ among people according to an individual's level of IT identity formation.

\section{Issues and concerns surrounding Free Basics}

Before we leave remarks about the implications of Free Basics for individual empowerment and social capital creation, let us see some major concerns surrounding Free Basics in viewing it as a development tool. In December 2015, around 50 faculty members of the Indian Institutes of Technology and the Indian Institute of Science released a statement regarding the three key problems of Free Basics [25], [26]. We will briefly address each of the three key issues here and see what implications can be derived for ICTD in general.

"Facebook assumes control of defining what a 'basic' service is. " [25] Closely related to this problem is the argument that Free Basics harms net neutrality, as Facebook the company plays a role as "a gatekeeper with too much leverage" [27]. This claim is supported by the fact that the company ultimately has the authority to review and add websites to the platform and this in turn may "disadvantage small content providers who may not be able to participate in such schemes." [28] In the field of ICTD and development aid in general, tied aid-_offering aid on the condition that it be used to procure goods or services from the provider of the aid" [29]-has been controversial because it generates unnecessary costs and inefficiency problems, and restricts choices of the beneficiaries. The issues generate a common concern that providers of technology and information may be deteriorating participants' freedom to make their own decisions about information access and usage. Moreover, the implementers might be hindering small local content providers from growing which in turn may generate gaps between what people can access to and what people need according to community context.

"Facebook would be able to decrypt the contents of the 'basic' apps on its servers. This flaw is not visible to the lay person as it's a technical detail, but it has deep and disturbing implications." [25] We recall that a similar concern was raised in the CI listserv discussion regarding the social media corporation's ability to manipulate the newsfeed. The issue implies that Facebook may be able to access and/or manipulate user created content and users' personal information stored as a result of using Free Basics platform. An article quoted Facebook's email message saying that Free Basics stores data on users' navigation information such as the name of the Third-Party Service accessed through Free Basics and the amount of data used in accessing or using that service [30]. Although it was stated in the article that the personal navigation information from within the service is not 
stored beyond 90 days [30], the fact that personal data is stored for a certain period of time generates concerns about potential problems. Taking the discussion to a broader context, privacy issue often arises in IT use and ICTD is not an exception. Whether inevitable or not, project implementers might be obtaining personal information while operating ICTD. Participants, although they might be ticking terms and conditions boxes, may not be fully aware of its potential consequences.

"The term 'free' in '[F]ree [B]asics' is a marketing gimmick...If something comes for free, its cost has to appear somewhere else. Telecom operators will have to recover the cost of 'free basic' apps from the non-free services...So effectively, whatever Facebook does not consider 'basic' will cost more." [25], [26] The statements point out that the cost covered by telecom operators in providing content without data charges to Free Basics' users should not be neglected. This may be translated into a cost to society whether in monetary terms (perhaps users potentially having to pay more for other services provided by the telecom operators) or structural terms (Indians "surrendering their digital freedom, and freedom in the digital economy, to Facebook" [26]). In ICTD, problem of societal cost could also be seen. For instance, One Laptop Per Child (OLPC) was an initiative to distribute low-cost computers to elementary school students in the developing world to support the students' access to knowledge and exploration of technologies [31]. However, various problems arose. For example, in Uruguay, $25 \%$ of the laptops deployed within the country were "not used by the schools because of malfunctioning and lack of technical support" [31] which meant money lost for the country which could have been spent in other meaningful ways. Also, concerns have been raised regarding the consequences of children being more exposed to Western values and norms through the use of internet and its possible implications on local cultures [31], [32] (recited from [31]). These implied societal costs to the developing nations in the form of confusion among users.

To summarize, we can see that Free Basics operation involves three key problems regarding potential restrictions on participants' choices, possible privacy risks, and potential societal costs, and that these issues are also evident in the broader context of ICTD.

\section{Discussion}

At the beginning of this paper we mentioned an encounter with an indigenous person, who said he just knows the basics: Word, Google, and Facebook. Facebook does many things for many people, and by offering access to the content for free without data charges, Free Basics may be transforming ICT experience for people in the developing world. By focusing on Facebook as one of the forefront services offered through Free Basics, and taking the discussion on the platform to the broader ICTD context, we can see potential benefits and harms that Free Basics may bring to the processes of individual empowerment and community development. As we have examined, areas of concern exist for Free Basics - and more specifically Facebook - to be regarded as a tool for development: potential restrictions on participants' choices, possible privacy risks, and potential societal costs. Yet, our analysis shows that individuals' Degrees of Self in terms of IT identity formation and corresponding activities on Facebook may influence how Facebook use leads to individual empowerment and social capital creation. Moreover, Facebook - and more broadly, Free Basics - at least provides opportunities for participants to experience empowerment through IT identity formation and to create and engage in social ties. Also, although Facebook the company ultimately has the authority to review and add websites to Free Basics, it does not completely exclude people from accessing, sharing, and creating information that are valuable to them. In this regard, it is difficult to say that the private company driven project does not contain any element of social good.

Based on the analysis presented above, there can be implications for ICTD and CI researchers. The first step is recognizing that technology does not determine its consequences by itself, and that the context is essential - in this paper, the context was illustrated as individuals' Degrees of Self in IT identity formation. Therefore, understanding the local context would be crucial for researchers when analyzing potential outcomes of technology for development projects. As a second step, the researchers should identify the limitations and risks of private company driven IT for development projects, while remaining open to exploring ways in which the activities open space for the participants to create values that are meaningful to them. It may not be possible to completely rule out the fact that Free Basics or ICTD are "intervening" into people's lives, but researchers can contribute towards understanding the "intentionality" of both the projects and the users, and highlight both contradictions and contributions the projects bring to individual and collective development.

One of the issues that needs to be closely examined is the disclosure of personal information by the participants following Free Basics use in particular, 
and ICTD initiatives in general. Our analysis shows that the issue of privacy would differ among people according to an individual's Degrees of Self in IT identity formation. Having this in mind, researchers can advise on varying levels of sensitive or private information released through Free Basics or ICT use, and possible consequences of such information disclosure. This would help reduce information asymmetry between implementers of Free Basics or ICTD initiatives and the participants, and help increase awareness regarding privacy issues among the people.

To summarize, ICTD and CI researchers can work towards increasing transparency among stakeholders of the deployment of Facebook's Free Basics services in particular and of ICTD interventions in general, calling out both the potential benefits and possible harms of ICT use on individual and community development. The IT identity theory offers a valuable tool to better understand the functionings of identity construction, and through it, the contribution of ICT to individual empowerment and social capital creation. While we agree to an extent that Free Basics may have potential contributions to development, this does not mean that we believe people should embrace it without any critical viewpoint.

\section{Conclusion}

Our discussion started with the controversies around Free Basics, which led us to think about prevailing issues surrounding ICTD in general. Tremendous amount of money has been spent on introducing ICT for social good, but there have been debates on whether such investments are truly effective in improving people's lives. More access to ICT resources is needed, coupled with opportunities for meaningful use that turns the ICT resources into solutions to everyday lives. IT identity offers an analytical framework to help analyze the potential contribution of ICT use to identity formation, a critical dimension of individual empowerment. In a similar way, social capital offers an analytical framework to better understand the possible contribution of ICT use to community development. By analyzing typology of Facebook use we found that the use of the technology might lead to individual empowerment and social capital creation, and yet the process and results much depend on the users and their context. We also learned that there are potential areas of concern such as respect for net neutrality and privacy. These can be areas where researchers in the relevant fields can cooperate to reduce information asymmetry and alert participants about possible harm from ICT use.
Free Basics case illustrates that projects driven by businesses may contain elements of social good, even though they may not necessarily generate actual social good for participants. Researchers can examine and inform both benefits and harms of Free Basics and ICTD initiatives for the participants to make more informed decisions. While we should be exploring possibilities that private company driven initiatives could support individual and community development, we must have in mind that merely having good intentions is not a sufficient condition for enriching people's lives.

\section{Acknowledgements}

An earlier version of this discussion appeared in the Journal of Community Informatics: M. Yim, R. Gomez, and M. Carter. "Facebook's "Free Basics": For or against community development?" The Journal of Community Informatics, vol. 12, no. 2, pp. 217-225, 2016.

\section{References}

[1] "Our mission," Internet.org. [Online]. Available: https://info.internet.org/en/mission/

[2] C. Matyszczyk, "Facebook's new ads aren't as friendly as they seem," CNET, 2015 February 15, retrieved from http://www.cnet.com/news/facebooks-new-ads-arentas-friendly-as-they-seem/

[3] J. Hempel, "Facebook renames its controversial Internet.org app," WIRED, 2015 September 24, retrieved from http://www.wired.com/2015/09/facebook-renamescontroversial-internet-org-app/

[4] "Free Basics by Facebook," Internet.org. [Online]. Available: https://info.internet.org/en/story/free-basicsfrom-internet-org/

[5] "Where we've launched," Internet.org. [Online]. Available: https://info.internet.org/en/story/where-wevelaunched/

[6] M. K. Sein and G. Harindranath, "Conceptualizing the ICT artifact: Toward understanding the role of ICT in national development," The Information Society, vol. 20, no. 1, pp. 15-24, 2004.

[7] G. Walsham and S. Sahay, "Research on information systems in developing countries: Current landscape and future prospects," Information Technology for Development, vol. 12, no. 1, pp. 7-24, 2006.

[8] A. Prakash and R. De', "Importance of development context in ICT4D projects: A study of computerization of land records in India," Information Technology \& People, vol. 20, no. 3, pp. 262-281, 2007.

[9] R. Gomez, "The changing field of ICTD: Growth and maturation of the field, 2000-2010," The Electronic Journal of Information Systems in Developing Countries (EJISDC), vol. 58, no. 1, 2013. 
[10] R. Gomez and S. Pather, "ICT evaluation: Are we asking the right questions?," in Proceedings of IDIA Conference 2010, Cape Town, South Africa, 2010.

[11] R. Heeks, "ICT4D 2.0: The next phase of applying ICT for international development," Computer, vol. 41, no. 6, pp. 26-33, 2008.

[12] A. Sey and M. Fellows, "Literature review on the impact of public access to information and communication technologies," Center for Information \& Society, University of Washington, Seattle, 2009.

[13] L. F. Baron and R. Gomez, "Relationships and connectedness: Weak ties that help social inclusion through public access computing," Information Technology for Development, vol. 19, no. 4, pp. 271-295, 2013.

[14] M. Carter and V. Grover, "Me, my self, and I(T): Conceptualizing information technology identity and its implications," MIS Quarterly, vol. 39, no. 4, pp. 931-957, 2015.

[15] A. Sen, Development as freedom. New York: Anchor Books, 2000.

[16] M. Carter, G. Grant, and S. Qureshi, "Panel: Emerging technologies for development: Challenges and opportunities," presented at the 49th Hawaii International Conference on System Sciences (HICSS), Kauai, Hawaii, January 5-8, 2016.

[17] "Free Basics platform," Internet.org. [Online]. Available: https://info.internet.org/en/story/platform/

[18] M. Carter, V. Grover, and J. B. Thatcher, "Mobile devices and the self: Developing the concept of mobile phone identity," in Strategy, adoption, and competitive advantage of mobile services in the global economy, I. Lee, Ed. Hershey, PA: IGI Global, 2012, pp. 150-164.

[19] J. S. Coleman, "Social capital in the creation of human capital," American Journal of Sociology, vol. 94, pp. S95-S120, 1988.

[20] R. D. Putnam, Bowling alone: The collapse and revival of American community. New York: Simon and Schuster, 2000.

[21] D. Williams, "On and off the'Net: Scales for social capital in an online era," Journal of Computer-Mediated Communication, vol. 11, no. 2, pp. 593-628, 2006.

[22] N. B. Ellison, C. Steinfield, and C. Lampe, "The benefits of Facebook 'friends:' Social capital and college students' use of online social network sites," Journal of Computer-Mediated Communication, vol. 12, no. 4, pp. 1143-1168, 2007.

[23] A. N. Joinson, "'Looking at', 'looking up' or 'keeping up with' people? Motives and uses of Facebook," in Proceedings of the SIGCHI Conference on Human Factors in Computing Systems, ACM, New York, 2008, pp. 1027-1036.

[24] P. B. Brandtzæg, "Social networking sites: Their users and social implications-A longitudinal study," Journal of Computer-Mediated Communication, vol. 17, no. 4, pp. 467-488, 2012.

[25] "Facebook's Free Basics plan: India academics see 'deep flaws," BBC News, 2015 December 30, retrieved from http://www.bbc.com/news/world-asia-india-35197062 [26] "Full text: Facebook's Free Basics will limit internet freedom, say 50 faculty of IITs and IISc," Scroll.in, 2015 December 30, retrieved from http://scroll.in/article/778805/full-text-facebooks-freebasics-will-limit-internet-freedom-say-50-faculty-of-iitsand-iisc

[27] A. LaFrance, "Facebook and the new colonialism," The Atlantic, 2016 February 11, retrieved from http://www.theatlantic.com/technology/archive/2016/02/fac ebook-and-the-new-colonialism/462393/

[28] A. Soni, "India deals blow to Facebook in peoplepowered 'net neutrality' row," The Guardian, 2016 February 8 , retrieved from https://www.theguardian.com/technology/2016/feb/08/india -facebook-free-basics-net-neutrality-row

[29] "Untied aid," Organisation for Economic Cooperation and Development (OECD). [Online]. Available: http://www.oecd.org/dac/untied-aid/

[30] R. Venkataramakrishnan, "Internet.org VP: We used the Facebook platform to lobby TRAI just like the people on the other side," Scroll.in, n.d., retrieved from http://scroll.in/article/778881/internet-org-vp-we-used-thefacebook-platform-to-lobby-trai-just-like-the-people-onthe-other-side

[31] N. Shah, "A blurry vision: Reconsidering the failure of the One Laptop Per Child initiative," WR: Journal of the Arts \& Sciences Writing Program, no. 3, pp. 89-98, $2010 / 2011$.

[32] K. L. Kraemer, J. Dedrick, and P. Sharma, "One Laptop Per Child (OLPC): A novel computerization movement?," in Proceedings of the 44th Hawaii International Conference on System Sciences (HICSS), 2011. 